\title{
Different Effect of Sox11 in Retinal Ganglion Cells Survival and Axon Regeneration
}

\author{
Ying Li', Felix L. Struebing ${ }^{1,2,3}$, Jiaxing Wang ${ }^{1}$, Rebecca King ${ }^{1}$ and Eldon E. Geisert' ${ }^{1 *}$ \\ ${ }^{1}$ Department of Ophthalmology, Emory University, Atlanta, GA, United States, ${ }^{2}$ Center for Neuropathology and Prion \\ Research, Ludwig Maximilian University of Munich, Munich, Germany, ${ }^{3}$ Department for Translational Brain Research, \\ German Center for Neurodegenerative Diseases, Munich, Germany
}

OPEN ACCESS

Edited by: Benjamin E. Reese, University of California, Santa Barbara, United States

Reviewed by: Peter Gerard Fuerst, University of Idaho, United States Patrick William Keeley University of California, Santa Barbara, United States

${ }^{*}$ Correspondence: Eldon E. Geisert egeiser@emory.edu

Specialty section: This article was submitted to Neurogenomics, a section of the journal

Frontiers in Genetics

Received: 03 September 2018 Accepted: 27 November 2018 Published: 18 December 2018

Citation:

Li Y, Struebing FL, Wang J, King R and Geisert EE (2018) Different Effect of Sox11 in Retinal Ganglion Cells Survival and Axon Regeneration. Front. Genet. 9:633. doi: 10.3389/fgene.2018.00633
Purpose: The present study examines the role of Sox11 in the initial response of retinal ganglion cells (RGCs) to axon damage and in optic nerve regeneration in mouse.

Methods: Markers of retinal injury were identified using the normal retina database and optic nerve crush (ONC) database on GeneNetwork ${ }^{2}$ (www.genenetwork.org). One gene, Sox 11, was highly upregulated following ONC. We examined the role of this transcription factor, Sox11, following ONC and optic nerve regeneration in mice. In situ hybridization was performed using the Affymetrix 2-plex Quantigene View RNA In Situ Hybridization Tissue Assay System. Sox11 was partially knocked out by intravitreal injection of AAV2-CMV-Cre-GFP in Sox $11^{\mathrm{f} / \mathrm{f}}$ mice. Optic nerve regeneration model used Pten knockdown. Mice were perfused and the retinas and optic nerves were dissected and examined for RGC survival and axon growth.

Results: Sox11 was dramatically upregulated in the retina following ONC injury. The level of Sox11 message increased by approximately eightfold 2 days after ONC. In situ hybridization demonstrated low-level Sox11 message in RGCs and cells in the inner nuclear layer in the normal retina as well as a profound increase in Sox11 message within the ganglion cells following ONC. In Sox $11^{f / f}$ retinas, partially knocking out Sox11 significantly increased RGC survival after ONC as compared to the AAV2-CMVGFP control group; however, it had little effect on the ability of axon regeneration. Combinatorial downregulation of both Sox11 and Pten resulted in a significant increase in RGC survival as compared to Pten knockdown only. When Pten was knocked down there was a remarkable increase in the number and the length of regenerating axons. Partially knocking out Sox11 in combination with Pten deletion resulted in a fewer regenerating axons.

Conclusion: Taken together, these data demonstrate that Sox11 is involved in the initial response of the retina to injury, playing a role in the early attempts of axon regeneration and neuronal survival. Downregulation of Sox11 aids in RGC survival following injury of optic nerve axons, while a partial knockout of Sox11 negates the axon regeneration stimulated by Pten knockdown.

Keywords: retinal ganglion cells, Sox11, optic nerve crush, axon regeneration, AAV2 


\section{INTRODUCTION}

Advances in our ability to monitor molecular changes in neurons have led to an increased understanding of the events that transpire following neuronal injury (Howell et al., 2011; Moore and Goldberg, 2011; Vazquez-Chona and Geisert, 2012; Munguba et al., 2013; Templeton et al., 2013). After axonal damage, the initial response of a central nervous system (CNS) neuron may be similar to that of a neuron in the peripheral nervous system (PNS) (Carlstedt, 1997). Ultimately, neurons in the PNS will regenerate their axons and survive, while those in the CNS do not regenerate their axons and the cell bodies die. The initial response of the CNS neurons to regenerate and eventual failure of this regenerative response was described by Ramón y Cajal and termed "abortive regeneration" (Ramón et al., 1928). When examining the initial response of neurons to injury, there are some common responses in the CNS and PNS. One transcription factor activated in both the CNS and PNS after injury is Sox11 (McCurley and Callard, 2010; Struebing et al., 2017). There is strong evidence that this gene is part of the transcriptional network activated by injury and involved in axonal regeneration in the PNS (Jankowski et al., 2009; Jing et al., 2012).

Sox11 is a member of the SRY-related box group C (SoxC) gene family of transcription factors (Schepers et al., 2002; PillaiKastoori et al., 2015). Among these, SOX11 and SOX4 play a critical role in the normal development of neurons and specifically retinal ganglion cells (RGCs) (Jiang et al., 2013; Usui et al., 2013a; Wang et al., 2013). SOX11 is expressed in retinal progenitor cells as part of the process leading progenitor cells to become neuroblasts (Haslinger et al., 2009; Usui et al., 2013b). In knockdown of either Sox 11 or Sox4, there is a moderate reduction in RGC number; however when both Sox 11 and Sox4 are knocked down, there is a complete loss of ganglion cell development (Jiang et al., 2013). During eye development, Sox11 is also required to maintain proper levels of hedgehog signaling, and mutations have been associated with coloboma due to improper optic fissure closure (Pillai-Kastoori et al., 2014; Wen et al., 2015). Furthermore, SOX11 is critical for axonal growth, driving the expression of axon growth-related proteins such as class III beta tubulin and MAP2 (Bergsland et al., 2006). SOX11 also plays a similar role in adult neurogenesis. High levels of SOX11 are found in the cells within the subventricular zone, the rostral migratory stream and within the neuroprogenitor zone of the dentate gyrus (Tanaka et al., 2004; Haslinger et al., 2009; Wang et al., 2013). These studies underline the importance of SOX11 in terminal differentiation of progenitor cells to neurons and axon extension.

In addition to functioning in neuronal differentiation, SOX11 has a prominent role in the response of neurons to injury. After peripheral nerve injury, SOX11 is immediately upregulated in the neuronal cell bodies as the axon is regenerating (Tanabe et al., 2003; Jankowski et al., 2009). Decreasing levels of SOX11 in the neuronal cell body result in slower axonal regeneration of peripheral nerves (Jankowski et al., 2009). Similar results are observed in tissue culture. When Sox11 is knocked down in cultured peripheral neurons, there is also a reduction in neurite growth and an increase in apoptosis (Jankowski et al., 2006). Conversely, overexpressing Sox11 in cultured dorsal root ganglion cells produces an increase in neurite growth, and in vivo overexpression of Sox11 accelerates the growth of regenerating axons (Jing et al., 2012). One intriguing anatomical experimental model is the dorsal root ganglion, where the central projection of the dorsal root ganglion enters the spinal cord (CNS) and the peripheral projection extends out into a peripheral nerve that is myelinated by Schwann cells. When the central rootlet is severed, there is a modest (51\%) increase in Sox 11 expression in the ganglion even when the central portion will not regenerate back into the spinal cord. However, when the peripheral root is damaged, a relatively massive (1004\%) increase in Sox11 is seen as the axons regenerate down the peripheral nerve (Jankowski et al., 2009).

In the present study, we examine the response of SOX11 in the retina following injuries to the axons of the optic nerve. We also explored the potential role of Sox11 in injured RGCs and regenerated axons. We propose that the upregulation of SOX11 after injury is an attempt of neurons to regenerate, but ultimately results in abortive regeneration and cell death.

\section{MATERIALS AND METHODS}

\section{Mice}

All procedures involving animals were approved by the Animal Care and Use Committee of Emory University and were in accordance with the ARVO Statement for the Use of Animals in Ophthalmic and Vision Research. BXD stains, including their parental strains, $\mathrm{C} 57 \mathrm{BL} / 6 \mathrm{~J}$ and $\mathrm{DBA} / 2 \mathrm{~J}$, were used for Gene network database. Sox $11^{\mathrm{f} / \mathrm{f}}$ mice used for Sox11 downregulation experiment and the regeneration study were obtained from Dr. Rafi Ahmed's labs, which were originally created by Veronique Lefebvre at Cleveland Clinic (Bhattaram et al., 2010). The mice were housed in a pathogen-free facility at Emory University, maintained on a $12 \mathrm{~h}: 12 \mathrm{~h}$ light-dark cycle, and provided with food and water ad libitum.

\section{Optic Nerve Crush}

The optic nerve crush (ONC) procedure was performed as previously described in Templeton and Geisert (Templeton and Geisert, 2012). Briefly, C57BL/6 or Sox $11^{\mathrm{f} / \mathrm{f}}$ (four mice per group) mice were deeply anesthetized with $15 \mathrm{mg} / \mathrm{kg}$ xylazine and $100 \mathrm{mg} / \mathrm{kg}$ ketamine for the surgery. An incision was made into the lateral aspect of the conjunctiva, and the eye was rotated nasally to expose the optic nerve. The optic nerve was then grasped for $10 \mathrm{~s}$ with Dumont cross-clamp \#7 forceps (Roboz, cat. \#RS = 5027, Gaithersburg, MD, United States), using only the spring action of the instrument to crush the nerve. The crush site is about $1 \mathrm{~mm}$ behind the eye to avoid injury to the ophthalmic artery as mentioned by Wang et al. (2018). The animals were allowed to recover on a water-circulated heating pad.

\section{In situ Hybridization}

In situ hybridization was performed using the 2-plex Quantigene View RNA ISH Tissue Assay kit (Affymetrix, Inc., Santa Clara, CA, United States). Assays were performed as per the manufacturer's instructions with stock solutions. Eyes were 
isolated from C57BL/ 6 mice $(n=6)$, both control and 2 days after ONC, and drop-fixed in 4\% Paraformaldehyde for $24 \mathrm{~h}$. Mid-way through the 24-h fixation, a 26-gauge needle was used to create a hole in the cornea, assisting with the fixation. Immediately after the 24-h period, the eyes were serially dehydrated in ethanol, cleared with xylenes embedded in paraffin. Blocks were sectioned on an American Optical series 1000 microtome (American Optical, Co., Buffalo, NY, United States) to a thickness of $5 \mu \mathrm{m}$ and mounted on Surgipath X-tra micro slides (Leica Biosystems Richmond, Inc., Richmond, IL, United States). Before beginning the hybridization protocol, the slides were baked at $60^{\circ} \mathrm{C}$ for $30 \mathrm{~min}$ to increase tissue adhesion. As per the manufacturer's protocol, the paraffin was removed from the slides with xylene before being boiled in a pretreatment solution (Affymetrix) for $10 \mathrm{~min}$ and incubated with Protein Kinase K (Affymetrix, Santa Clara, CA, United States) at $40^{\circ} \mathrm{C}$ for $10 \mathrm{~min}$. Custom probes for Sox11 and Chrna6 (Affymetrix, Santa Clara, CA, United States) were then hybridized to the tissue. Signal amplification was accomplished by hybridizing Type 1 and Type 2 specific pre-amp oligonucleotides, amp oligonucleotides and label oligonucleotides sequentially, achieving a 400-fold signal amplification from each mRNA molecule. Sections were viewed with an Olympus BX51 microscope (Olympus America, Inc., Melville, NY, United States).

\section{Sox11 Partial Knockout}

To downregulate Sox11, Sox $11^{\mathrm{f} / \mathrm{f}}$ mice received intravitreal injections of AAV2-CMV-GFP-Cre $\left[2 \mu \mathrm{l}\right.$ of $10^{12} \mathrm{vg} / \mathrm{mL}$, expressing Cre recombinase with GFP from a bicistronic vector (Addgene plasmid \#49056), produced by Fred Gage (Kaspar et al., 2002)]. For the control animals, a vector expressing only GFP (AAV2-GFP under the CMV promoter) was used. Two weeks following intravitreal injection, optic nerves were crushed. For analysis of transduction efficiency, we included four injected animals (four eyes). Images from five randomly selected fields of each retina were taken at $20 \mathrm{x}$ magnification. The average transduction efficiency of AAV2 vector was 54\%, based on the number of GFP-positive and RBPMS-positive cells in flat-mount retinas (Figure 1).

\section{Pten Deletion Induced Regeneration Model and Quantitation of Axon Regeneration}

We used AAV2-shRNA-Pten-GFP (Pten short hairpin RNA-GFP packaged into $\mathrm{AAV}_{2}$ backbone constructs, titer $=1.5 \times 10^{12} \mathrm{vg} / \mathrm{ml}$ ) for Pten knockdown. The shRNA target sequence is $5^{\prime}$-AGG TGA AGA TAT ATT CCT CCA A-3' as described by Zukor et al. (2013). Deletion of Pten is showed to promote robust axon regeneration after ONC (Park et al., 2008). Two weeks before ONC, the mice were intravitreally injected with $2 \mu \mathrm{l}$ AAV-shRNA-Pten-GFP. Optic crush was performed. Zymosan (Sigma, St. Louis, MO, United States; Z4250, Lot \# BCBQ8437V) along with cAMP analog CPT-cAMP (Sigma, C3912, Lot \# SLBH5204V) total volume $2 \mu \mathrm{l}$ were injected into vitreous immediately following ONC to induce an inflammatory response and augment regeneration. Twelve days after ONC

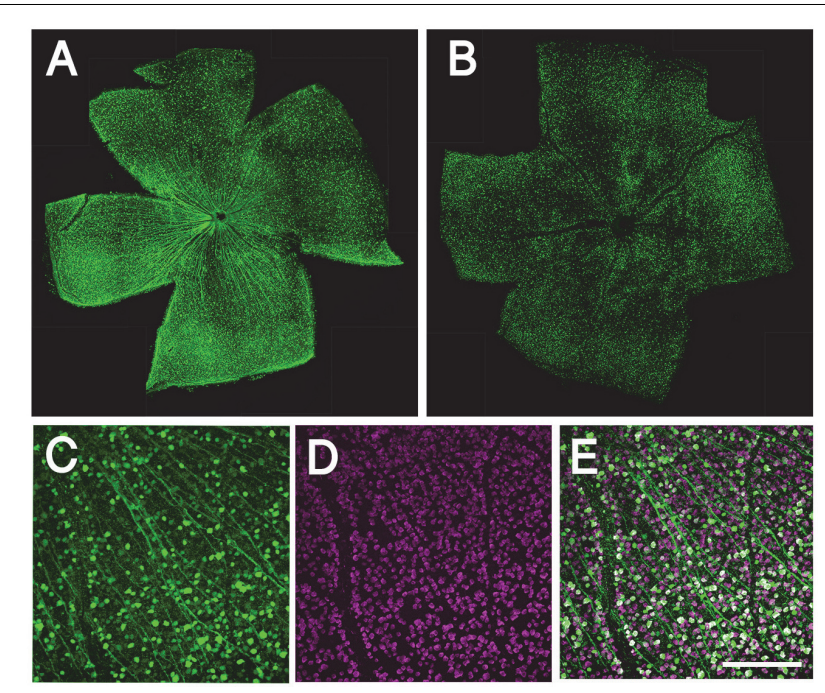

FIGURE 1 | Whole mount retinal immunohistochemistry showing AAV transduction in RGCs. (A) Confocal image of whole mounted retina showing transduction of AAV2-CMV-GFP. (B) Confocal image of whole mounted retina showing transduction of AAV2-shRNA-Pten-GFP. (C) Confocal image of flat mounted retina showing GFP expressing in RGCs. (D) RBPMS label RGCs specifically as a marker. (E) More than half of RGCs are transduced by AAV and express GFP; merge image. Scale bar $=100 \mu \mathrm{m}$.

(2 days before euthanasia), Alexa Fluor ${ }^{\circledR}$ 647-conjugated Cholera Toxin B (CTB; Thermo Fisher, Waltham, MA, United States; C34778) was injected into the vitreous for anterograde labeling of the regenerated axons. At 14 days after $\mathrm{ONC}$, the mice were deeply anesthetized with a mixture of $15 \mathrm{mg} / \mathrm{kg}$ of xylazine and $100 \mathrm{mg} / \mathrm{kg}$ of ketamine and perfused through the heart with PBS (Phosphate Buffered Saline, diluted to $1 \mathrm{x}$ from 10x stock, Corning, Manassas, VA, United States, $\mathrm{pH}$ 7.3) followed by $4 \%$ paraformaldehyde in phosphate buffer ( $\mathrm{pH}$ 7.3).

\section{Immunohistochemistry}

For the retina whole mount, retina tissues were removed from the globe after deeply anesthesia and perfusion with $4 \%$ paraformaldehyde, and fixed in $4 \%$ paraformaldehyde at room temperature for $1 \mathrm{~h}$. Following post-fixation, intact retinas were extracted and washed in PBST (Phosphate Buffered Saline with Tween 20) with $0.5 \%$ Triton X-100. Retinas were blocked in 5\% BSA (Sigma) and 10\% donkey serum in PBS for $2 \mathrm{~h}$ followed by incubation with primary antibodies for $24 \mathrm{~h}$ at $4^{\circ} \mathrm{C}$. The following primary antibodies and dilutions were used: antiGFP (Novus Biologicals, Littleton, CO, United States; Cat. \# NB100-1770, 1:1000), anti-RBPMS (Millipore, Cat \# ABN1376, Burlington, MA, United States, 1:1000). Then retinas were washed in PBST three times $10 \mathrm{~min}$ each, and incubated in secondary antibodies in PBST overnight at $4^{\circ} \mathrm{C}$. After another triplicate wash, retinas were carefully flattened and mounted on microscopy slides with Fluoromount (Southern Biotech, Birmingham, AL, United States) and imaged using a Nikon Eclipse Ti (Nikon, Inc., Melville, NY, United States) confocal microscope. 


\section{Counting Surviving RGCs and Regenerating Axons for Statistical Analysis}

Retinal flat-mounts were immunostained with RBPMS antibody (Millipore, Cat \# ABN1376, Burlington, MA, United States) to label RGCs. For each retina, five fields, whose distance to the optic nerve were equal, were randomly sampled from middle regions of each retina under 20x magnification. The density of RGCs per field was calculated according to the number of RGCs per field. The GFP and RBPMS double-labeled cells were counted as well, as the transduced cell results.

Optic nerves along with the optic chiasm were dissected and post-fixed in $4 \%$ paraformaldehyde overnight. The optic nerve was cleared with FocusClear ${ }^{\mathrm{TM}}$ (CelExplorer, Hsinchu, Taiwan) until totally transparent. FocusClear allows us to scan the whole thickness of the optic nerve for better understanding of the status of axon regeneration and provide clear imaging of regenerated axons from the optical slices scanned by confocal microscope for counting. The quantitation of axon regeneration was determined by counting the longest five axons or the longest single axon along the whole nerve. Both the distance the axons traveled and the number of axons at 0.5 and $1 \mathrm{~mm}$ behind the crush site were measured as described in Wang et al. (2018). Pseudocolor of green was used to show the CTB-labeled axons in all the optic nerve images of this study for clear visual observation. Data are presented as mean \pm standard error of the mean (SEM). Differences in axon counts, regeneration distance, and transduction efficiency were analyzed with the Mann-Whitney $U$-test using SPSS Statistics package 24.0 (SPSS, IBM, Chicago, IL, United States). A p-value of less than 0.05 was considered statistically significant.

All the experiments were done following standard biosecurity and institutional safety procedures.

\section{RESULTS}

\section{The Distinct Expression Changes of Sox11 Following Injuries to the Axons of the Optic Nerve}

To define the changes in Sox 11 that occur following injury to the optic nerve, we compared Sox11 mRNA levels in normal mice to Sox11 levels following ONC using the bioinformatic tools on GeneNetwork $^{1}$. The levels of Sox 11 mRNA were examined using the Normal HEI Retina (April, 2010) Database and comparing it to the ONC HEI Retina (April, 2012) Database (Freeman et al., 2011; Templeton et al., 2013). Sox11 was one of the genes with the largest change in expression 2 days after ONC. In the normal retinal dataset, the mean expression for Sox11 (detected by Illumina probe ILMN_1235647) across the BXD RI strains was 8.4 on a $\log _{2} Z$-scale (The mRNA expression levels are expressed on a custom $\mathrm{Z}$-scale according to the formula $2 \mathrm{Z}+8$ so that the mean expression of all mRNAs on the array equals 8) (Parker et al., 2017). In the C57BL/6 parental strain, the expression level

${ }^{1}$ http://genenetwork.org in the normal retina was 8.59 and for the DBA/2J strain the mean expression level was 8.54. Two days after ONC, there was a dramatic increase in the level of Sox11 expression (Figure 2), with the mean expression across the BXD strains being 11.03, which corresponded to an approximately eightfold increase. The same increase was observed in individual strains. The C57BL/6 strain had an expression level of 11.33 after ONC and the expression in the DBA/2J strain increased to 11.44 . These data indicate that Sox11 is dramatically upregulated after a specific injury to the ganglion cell axons within the optic nerve.

\section{Expression Pattern of Sox11 in Naïve Adult Retina and Injured Adult Retina}

In situ hybridization was used to identify the cells expressing Sox11 after injury to the retina. For the in situ hybridization, we examined retinas 2 days after ONC (Figure 3B) and compared it to uninjured control retinas (Figure 3A). Using the Affymetrix 2-plex Quantigene View RNA ISH Tissue Assay kit, we labeled cells expressing the RGC marker Chrna6 blue and Sox11 red (Figure 3) (Munguba et al., 2013). In the control retina, many of the cells in the ganglion cell layer were heavily labeled for Chrna6, and a few of the cells expressed marginal levels of Sox11. Two days after ONC there was a dramatic decrease in the labeling for Chrna6 and a substantial increase in the amount of labeling for Sox11. This change was similar trend to the changes in message levels observed in our microarray databases on GeneNetwork.org. In the normal retina database, Chrna6 (probe ILMN_2732438) was expressed at relatively high levels (mean value of 11.04) and 2 days following ONC, the expression decreased twofold (mean value of 9.96). These data from the in situ hybridization mirror our microarray expression analysis results.

\section{Downregulation of Sox11 Facilitates RGC Survival Following Optic Nerve Crush}

To define the role of Sox11 in the response of RGC to Injury, an AAV2 vector expressing Cre and GFP was used for Sox11 partial knockout in RGCs of the Sox $11^{\mathrm{f} / \mathrm{f}}$ mice (Figure 4). The retinas containing Sox11 partial knockout cells were compared to retinas treated in a similar manner using AAV2-GFP vectors. Two weeks after the intravitreal injection of the AAV2-Cre-GFP or AAV2-GFP vectors, the optic nerve was crushed. Following a 26-day survival, the eyes were injected with fluorescencelabeled CTB and the animals were sacrificed 2 days later. These data were compared to control retinas injected with AAV2-GFP vector that did not receive a nerve crush (Figure 4B). The flat mounted retinas were immunostained for RBPMS to label RGCs. When examining the retinas, we found an increased number of GFP-labeled RGCs in the Sox11 partial knockout animals relative to the GFP control animals (Figures 4B,C). It is also the case for all of the RBPMS labeled RGCs (Figures 4B,D). There were fewer RGCs left in the GFP control retinas relative to the retinas where Sox11 was partially knocked out. These results were quantified, counting the number of GFP-labeled RGCs (double labeled by GFP and RBPMS, Figure 4C) and total RGCs (labeled by RBPMS, Figure 4D) to define the effects of partially knocking 
A

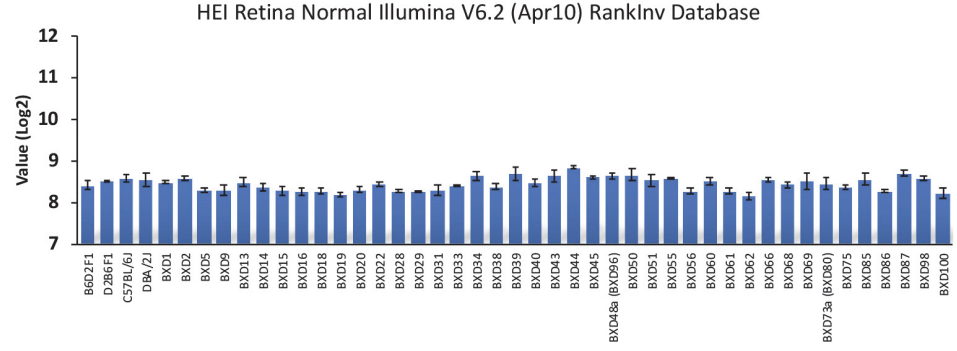

ONC HEI Retina (April 2012) RankInv Database

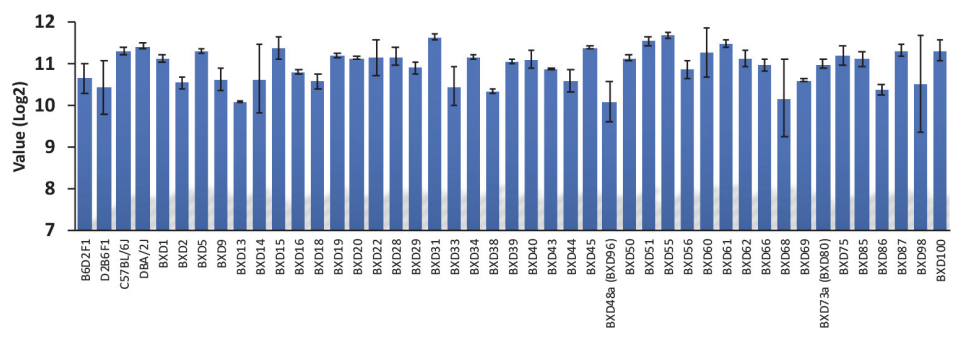

B

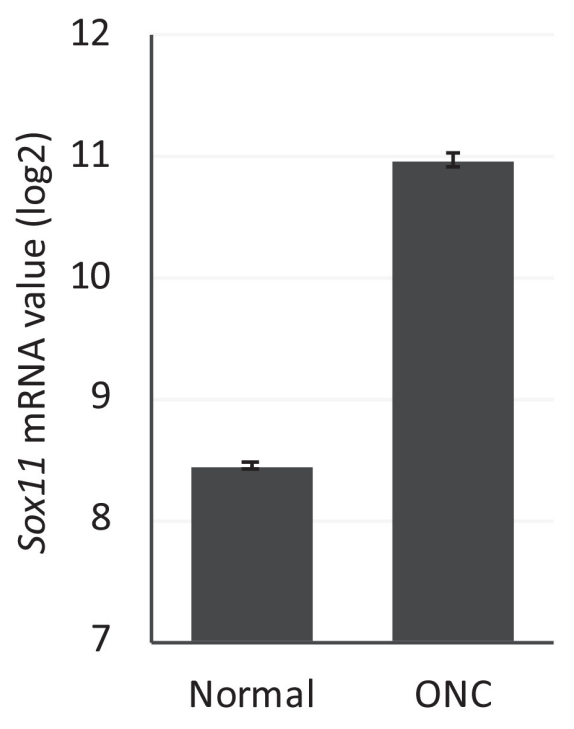

FIGURE 2 | Sox11 expression in the normal retina and after optic nerve crush (ONC). (A) The ordinate represents mRNA levels from microarrays, expressed in a log 2 scale with the mean set to 8 . The mice used to generate these data were C57BL/6, DBA/2J, their respective F1 crosses, BALB/cByJ, and members of the BXD recombinant inbred strain line. The top graph denotes the expression levels of Sox 11 under normal conditions, while the bottom graph denotes the expression of Sox11 2 days after the ONC. (B) Note the dramatic increase in expression following injury, from a normal mean expression value of 8.4 to a mean expression value of 11.0 after nerve crush, which corresponded to an approximately eightfold increase.

out Sox11. The normal retinas (without ONC) had 1782 GFPlabeled RGCs $/ \mathrm{mm}^{2}$ (SE 130 Cells $/ \mathrm{mm}^{2}, n=4$ ). In the crushed retinas that received AAV2-GFP, the average number of GFPlabeled RGCs was $158 / \mathrm{mm}^{2}$ (SE 15.7 Cells $/ \mathrm{mm}^{2}, n=4$ ); while, in the retinas receiving AAV2-Cre-GFP, the average number of GFP-labeled RGCs $357 \mathrm{RGCs} / \mathrm{mm}^{2}$ (SE $7.1 \mathrm{Cells} / \mathrm{mm}^{2}, n=4$ ). This $125.9 \%$ increase in RGC survival between AAV2-GFP group and AAV2-Cre-GFP group is statistically significant $(p=0.029$, Mann-Whitney $U$-test, $n=4$, Figure 4C). Interestingly, if we examine the number of RBPMS-labeled RGCs in the same retinas (Figure 4D), with a dramatic decrease caused by the ONC, a similar protective effect observed in the retinas in which Sox11 was knocked down using AAV2-Cre-GFP (Figure 4D). Without ONC, the retinas had 3389 RBPMS-labeled RGCs $/ \mathrm{mm}^{2}$ (SE 92.1 Cells $\left./ \mathrm{mm}^{2}, n=4\right)$. In the crushed retinas that received AAV2GFP, the average number of total RGCs was $828 / \mathrm{mm}^{2}$ (SE 22.9 Cells $\left./ \mathrm{mm}^{2}, n=4\right)$; while, in the retinas receiving AAV2-CreGFP, the average number of total RGCs $1398 \mathrm{RGCs} / \mathrm{mm}^{2}$ (SE 62.9 Cells $\left./ \mathrm{mm}^{2}, n=4\right)$. Partial knockout Sox 11 had a significantly positive effect on the survival of the RGC cell body 14 days after ONC ( $p=0.028$, Mann-Whitney $U$-test, $n=4)$. Thus, a partial knockout of Sox11 not only rescued the transduced cells missing Sox11 but there was also a significant increase in survival of non-transduced RGCs in retinas.

\section{Sox11 Partial Knockout Does Not Facilitate Axon Regeneration}

When we examined the optic nerve in the same set of mice, we did not observe any significant increase in axonal regeneration

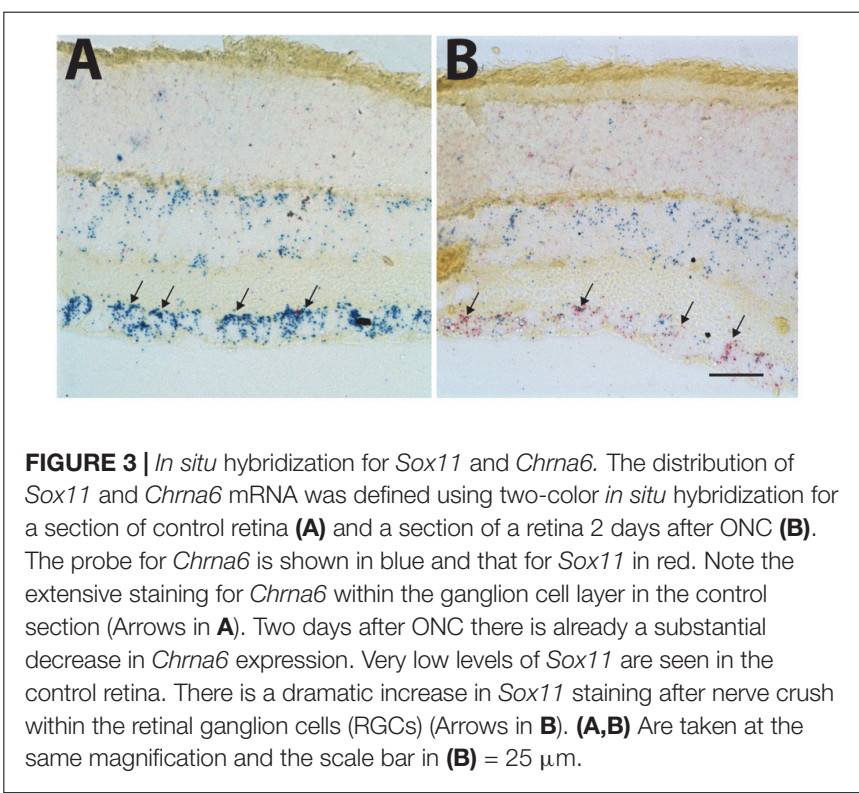

that was due selectively to the partial knockout Sox11. We examined axon regeneration following ONC in four groups of mice: C57BL/6J controls; Sox $11^{\mathrm{f} / \mathrm{f}}$ controls; Sox $11^{\mathrm{f} / \mathrm{f}}$ that received an intravitreal injection of AAV2-GFP; and, Sox $11^{\mathrm{f} / \mathrm{f}}$ that received an intravitreal injection of AAV2-Cre-GFP. The number of regenerating axons in the damaged optic nerve and the distance the axons traveled along the nerve was measured. There was very little axonal regeneration in the control groups and no 


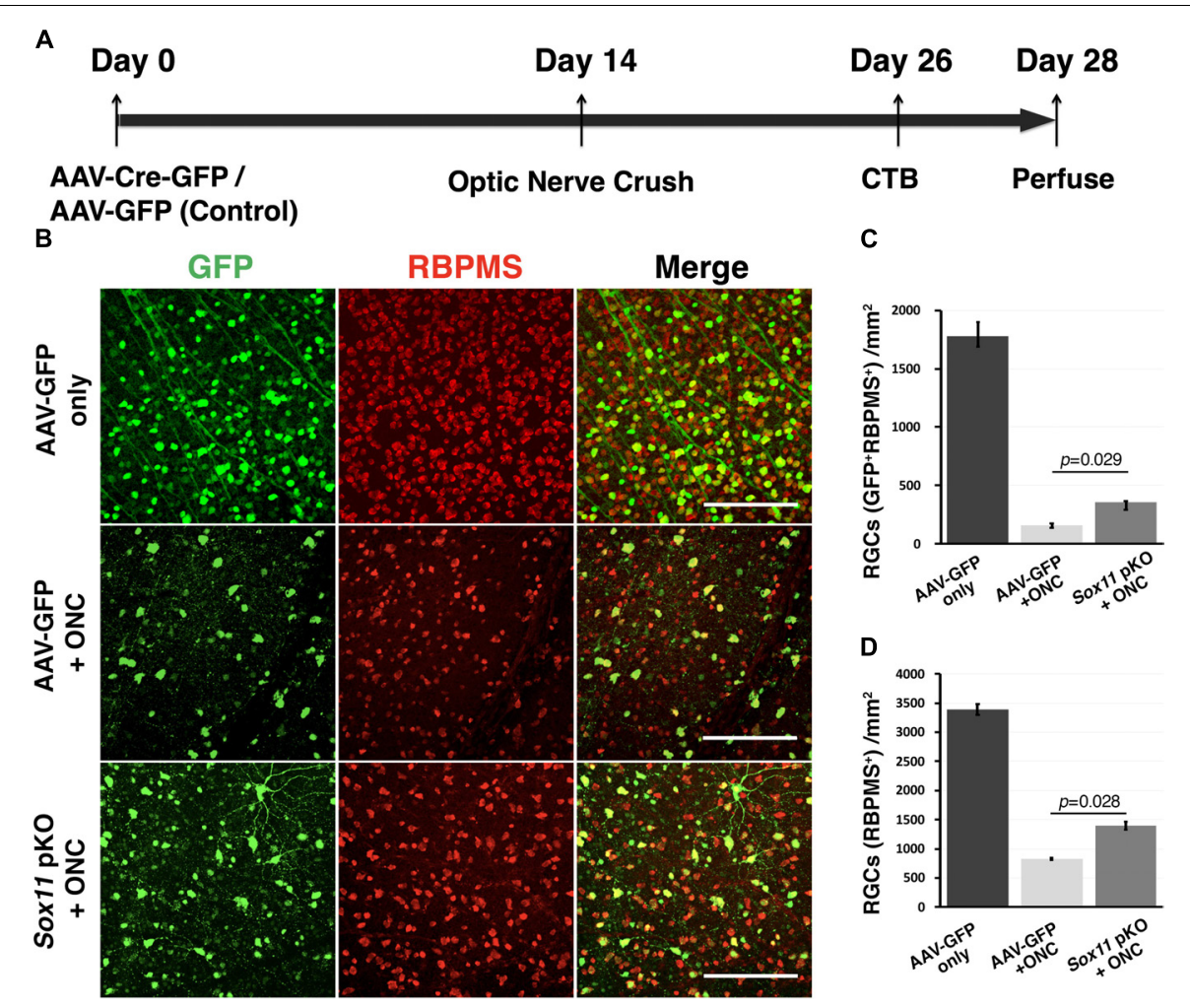

FIGURE 4 | Downregulation of Sox11 facilitates RGC survival following ONC. (A) Sox11 is partially knocked out by intravitreal injection of AAV2-CMV-Cre-GFP in 4 to 6 -week-old Sox $11^{\mathrm{f} / \mathrm{f}}$ mice. The control group receives AAV2-CMV-GFP. Optic nerve crush is performed 2 weeks after viral vector injection. Twelve days after ONC, Alexa Fluor 647-conjugated cholera toxin B (CTB) is used to label regenerating axons. Two days later mice are sacrificed. (B) For the retinal whole mounts, RGCs are labeled with the pan-RGC marker RBPMS. The number of AAV2-GFP vector transduced RGCs without crush injury is $1782 \pm 117.5 / \mathrm{mm}^{2}$. (C) Downregulation of Sox11 in RGCs greatly increases the survival of AAV2 vector transduced RGCs (double labeled by GFP and RBPMS) after ONC as compared to AAV2-CMV-GFP injection with ONC group (357 $\pm 7.1 / \mathrm{mm}^{2}$ vs. $158 \pm 15.7 / \mathrm{mm}^{2}, n=4, p=0.029$, Mann-Whitney $U$-test). (D) The number of total RGCs labeled by RBPMS without crush injury is $3389 \pm 92.1 / \mathrm{mm}^{2}$. When comparing the total RGCs labeled by RBPMS, it shows that Sox11 partial knockout in the Sox $11^{\mathrm{f} / \mathrm{f}}$ mice significantly increases RPBMS-positive RGC survival after ONC as compared to AAV2-CMV-GFP ONC group $\left(1398 \pm 63 / \mathrm{mm}^{2} \mathrm{vs} .828 \pm 23 / \mathrm{mm}^{2}, n=4, p=0.028\right.$,

Mann-Whitney $U$-test). Scale bar $=100 \mu \mathrm{m}$.

statistical difference between the C57BL/6J controls and the $\operatorname{Sox} 11^{\mathrm{f} / \mathrm{f}}$ controls. There was a significant difference $(p<0.05$, Mann-Whitney $U$-test, $n=4$ ) between these two control groups and the $\operatorname{Sox} 11^{\mathrm{f} / \mathrm{f}}$ mice that received intravitreal injections of either AAV2-GFP or AAV2-Cre-GFP. However, there was no difference in the partial knockout of Sox11 compared to the GFP control groups (Figure 5). These data suggest that a partial knockout of Sox11 does not facilitate axon regeneration in the injured optic nerve. Furthermore, the AAV treatment alone (either AAV2-GFP treated Sox $11^{\mathrm{f} / \mathrm{f}}$ mice or AAV2-Cre-GFP Sox $11^{\mathrm{f} / \mathrm{f}}$ mice) produces a significant increase in regeneration compared to ONC only mice (non-treated C57BL/6J mice or non-treated Sox $11^{\mathrm{f} / \mathrm{f}}$ mice). We do not fully understand this effect of AAV in the Sox $11^{\mathrm{f} / \mathrm{f}}$ mice; however, it is a consistent result. We assume that there is some interaction between the AAV vector and the genome of the $\operatorname{Sox} 11^{\mathrm{f} / \mathrm{f}}$ mice, facilitating axon regeneration.

\section{Downregulation of Sox11 Suppresses Induced Axon Regeneration}

To examine the potential contribution of Sox11 to optic nerve axonal regeneration, a combined partial knockout of both Sox11 and Pten was examined. Knocking down Pten with the AAV2shRNAPten vector resulted in a significant amount of axonal regeneration 2 weeks after ONC. The eyes that received AAV2GFP and AAV2-shRNAPten had a significant increase in the number of axons regenerating $0.5 \mathrm{~mm}$ from the crush site and an increase in the distance that longest axon traveled (Figure 6A). In the GFP control optic nerve the number of axons at $0.5 \mathrm{~mm}$ from the crush site was $261 \pm 19(n=4)$ and the longest regenerating axon found in the optic nerve was on average $0.92 \mathrm{~mm}$ (Figure 6A). Following AAV2-shRNAPten, the number of axons at $0.5 \mathrm{~mm}$ increased to $908 \pm 24(n=4)$ and the longest axon was on average $2.18 \mathrm{~mm}$ from the crush site. When Sox 11 was partially knocked out in mice that also received the AAV2-shRNAPten treatment, there was a surprising decrease in the regenerative response in the optic nerve (Figure 6A). In the Sox 11 partial knockout optic nerve the number of axons at $0.5 \mathrm{~mm}$ from the crush site was $384 \pm 47(n=4)$ and the longest regenerating axon found in the optic nerve was on average $1.09 \mathrm{~mm}$ (Figures 6B-E). This represents a significant decrease in the number of regenerating axons ( $p=0.02$, Mann-Whitney $U$-test, $n=4)$ and the distance traveled ( $p=0.021$, Mann-Whitney $U$-test, $n=4$ ). 

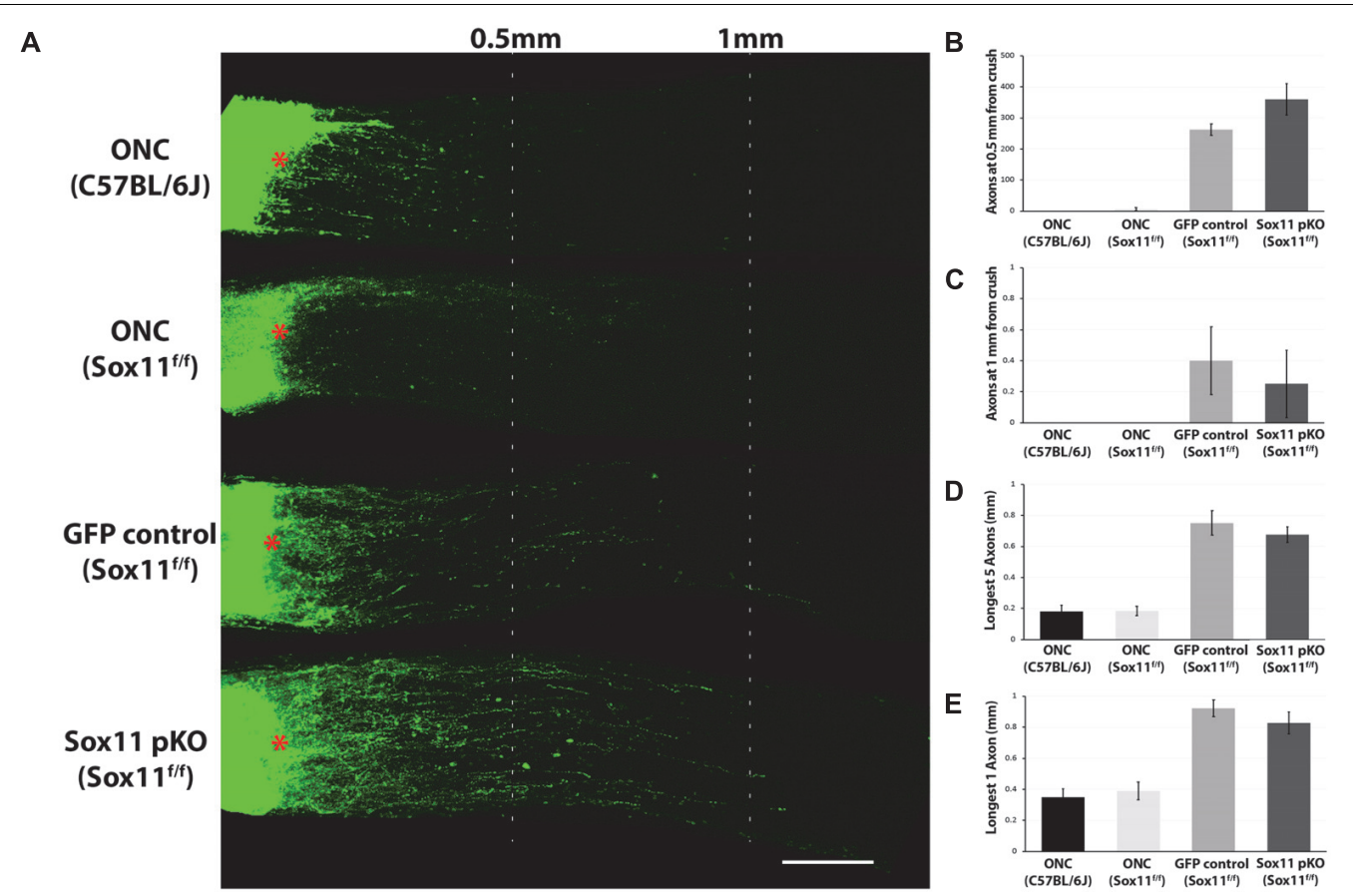

FIGURE 5 | Representative images of optic nerves showing regenerating axons from different groups at 2 weeks after injury. (A) Pseudocolor green was used for the CTB-labeled axons in all the optic nerve images of this study for clear visual observation (red asterisks represent the crush site). Quantification axon number at $0.5 \mathrm{~mm}(\mathbf{B})$ and $1 \mathrm{~mm}$ (C) from crush site reveals that there is a statistically significant increase in the number of axons following an injection of either AAV2-GFP or AAV2-Cre-GFP in the Sox $11^{\mathrm{f} / \mathrm{f}}$ mice relative to ether the C57BL/6J control of the Sox $11^{\mathrm{f} / \mathrm{f}}$ control. This indicates that the increased axon regeneration is due to the use of AAV2-gene delivery systems in the retina and not the partial knockout of Sox11. A similar result was observed for the distance of longest five regenerating axons traveled (D) and the distance of longest single regenerating axons (E). Again, the most regeneration was observed in the animals that received gene delivery in the retina by AAV2 vectors. There was a significant difference $\left(p<0.05, n=4\right.$, Mann-Whitney $U$-test) between the ONC only mice and the Sox $11^{\mathrm{f} / \mathrm{f}}$ mice that received intravitreal injections of either AAV2-GFP or AAV2-Cre-GFP. No statistic difference was found between the two ONC only groups. No statistic difference was found between the Sox11 pKO and the GFP control groups. $N=4$ per group. Scale bar $=200 \mu \mathrm{m}$.

The decrease in axonal regeneration observed in the Pten/Sox 11 double knockdown group was not due to a decrease in the number of surviving RGCs at 2 weeks following crush (Figure 7). In the animals that received AAV2-shRNAPten only, the average number of surviving RGCs was $722 \pm 77 / \mathrm{mm}^{2}$. Partial knockout of Sox11 in addition to Pten knockdown resulted in an increase in RGC survival with an average of $1393 \pm 94 / \mathrm{mm}^{2}$ RGCs. This increased survival was statistically significant ( $p=0.034$, Mann-Whitney $U$-test, $n=4$ ) (Figure 7C). The data of RGCs number in all experimental groups were summarized in Figure 8.

\section{DISCUSSION}

Sox family members are key regulators of neuron differentiation during development and axon regeneration after injury (Jankowski et al., 2006; Moore and Goldberg, 2011; Mu et al., 2012; Kuwajima et al., 2017; Wang et al., 2018). They are intimately involved in RGC differentiation and in the formation of the optic nerve (Chang et al., 2017). In the present study, we demonstrate that Sox11 is upregulated following retinal injury. For RGCs, there are many known markers, such as: Chrna6, Pou4f1, Tubb3, Thy1, or Sncg (Barnstable and Drager, 1984;
Gan et al., 1996; Mu et al., 2004; Surgucheva et al., 2008; Prasov and Glaser, 2012; Jiang et al., 2013; Munguba et al., 2013). Using these marker genes, we performed a meta-analysis of their expression in injured and uninjured retinas. Our injury paradigms included controlled ONC procedures that are known to induce RGC apoptosis (Hines-Beard et al., 2012; Templeton and Geisert, 2012). As expected, the expression of these RGC markers decreases as the ganglion cells die. Our data indicate an overall reduction in expression of these markers, both 2 and 5 days after retinal insult (Geisert et al., 2009). Specifically, a threefold reduction in Sncg expression is observed, Chrna6 and Pou4f1 are downregulated twofold, and, while not as robust, Thy 1 and Tubb3 also show a decrease in expression. Collectively, these data demonstrate that known RGC markers decrease as the optic nerve degenerates.

Unlike these RGC markers, Sox11 levels increase substantially following the initial injury to the retina or optic nerve. Two days after ONC, there was an almost eightfold upregulation of Sox11. We wondered if this increase in expression was specific to the severity of retinal injury, and queried a publicly available microarray dataset of glaucomatous mice presented by Howell and colleagues as an independent test on the role of Sox11 in the response of the retina to injury (Howell et al., 2011). In this DBA/2J mouse model of pigment dispersion glaucoma, there 


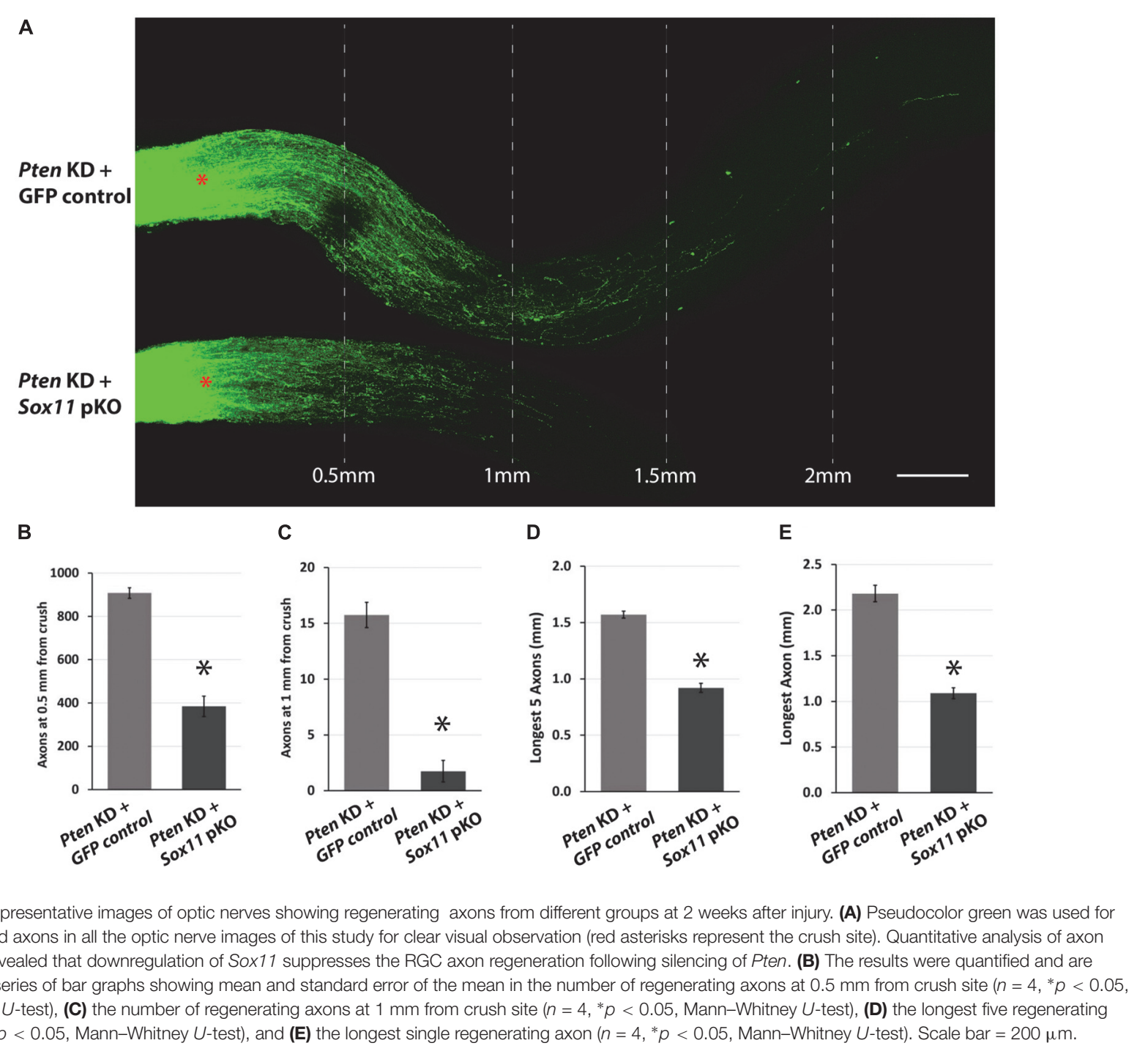

were relatively low levels of Sox 11 in the control mice and in mice that did not have detectable levels of ganglion cell loss (Figure 9). However, in mice with moderate ganglion cell loss, levels of Sox11 were approximately fourfold higher than in control animals. In animals with severe glaucoma, the level of Sox11 decreased to near control levels. These data suggest that the levels of Sox11 decrease as the ganglion cells die. This transient upregulation of Sox11 in moderate cases demonstrates the exquisite ability of Sox11 to mark injured, potentially dying neurons. A similar pattern was observed following ONC in C57BL/6 and DBA/2J where Sox11 is upregulated over twofold 2 days after nerve crush and over threefold 5 days after nerve crush (Templeton et al., 2013). Previous studies have implicated artificially high levels of Sox11 to promote regeneration in PNS (Jankowski et al., 2009; Jing et al., 2012; Chandran et al., 2016) and corticospinal axons (Wang et al., 2015). Gene profiling showed that Sox11 overexpression activated a set of developmental genes which are possibly related to axon growth and that it downregulated genes involved in synaptic transmission. This was consistent with the notion of a developmental process switch from axon growth mode of immature neurons to dendrite or synapse growth mode in mature neurons. Thus, Sox11 may be regarded as a master reprogramming regulator in the nervous system. Therefore, these data confirm our hypothesis that upregulation of Sox11 after injury is an attempt by neurons to regenerate.

What is the potential role of SOX11 following injury to the RGCs and the axons? Due to our result that injury caused upregulation of Sox11 in different injury models, we downregulated Sox11 2 weeks before ONC injury by Cre/LoxP system in vivo in order to validate our finding. After injury, the downregulation of Sox11 resulted in a higher survival rate of RGCs; however, no effect was seen on axon regeneration. Interestingly, we found that partially knocking out Sox11 not only increased the survival of transduced cells but also had increased the survival rate of cells not transduced by the AAV2Cre-GFP. External signals from microenvironment together with intrinsic signaling pathways determine whether a particular neuron will die (Pfisterer and Khodosevich, 2017). This is a 


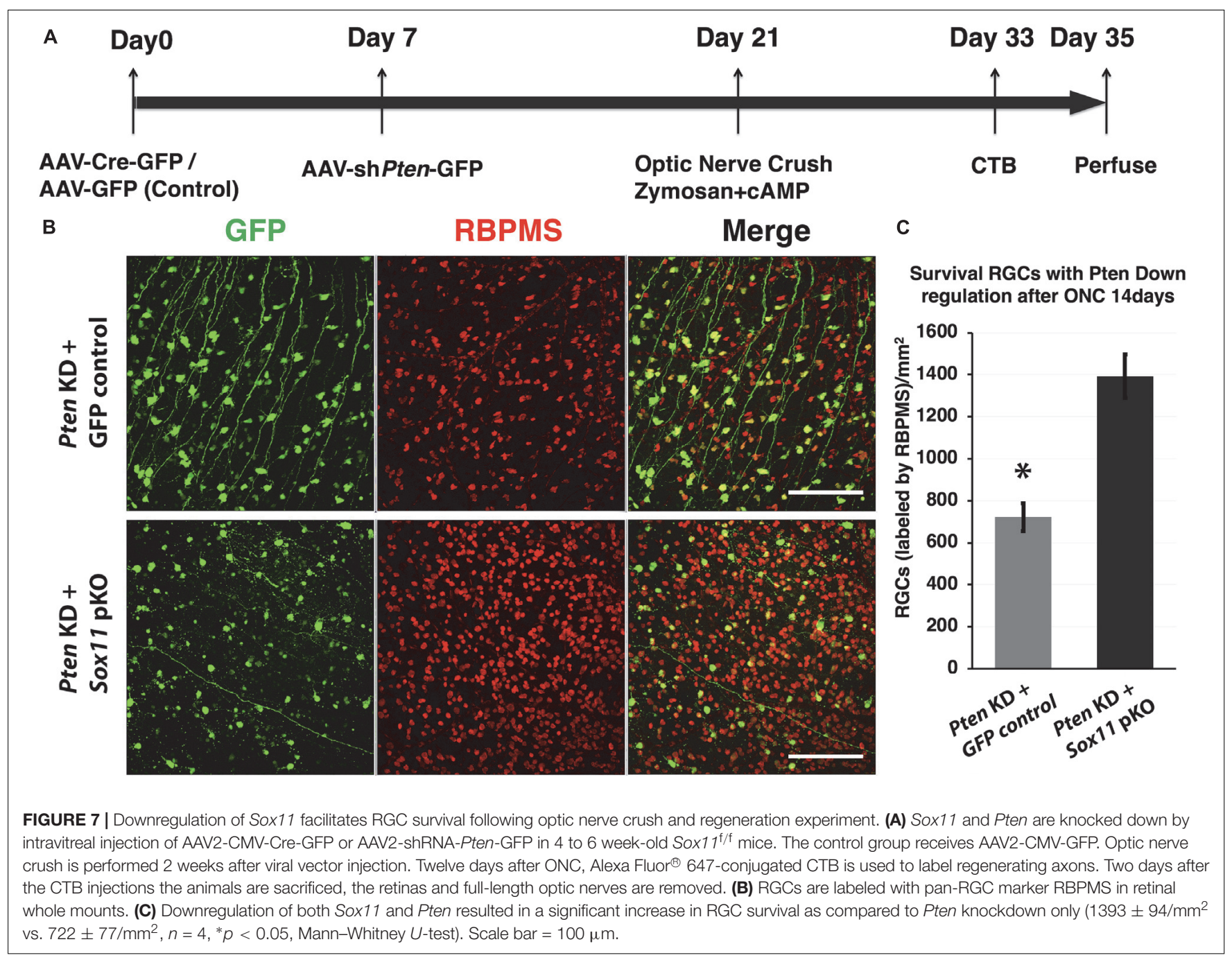

clear indication that there is a cell intrinsic effect of partially knocking out Sox11, as can be seen in the increased survival of cells in which Sox11 is knocked out. There is also a clear cell extrinsic effect with an increased survival of the non-transduced RGCs following the partial knockout of Sox11. These effects may be due to altered expression of Sox11 downstream targets. Several studies have identified downstream targets of Sox11 using ChIP-seq technologies (Bergsland et al., 2011; Kuo et al., 2015), including FGF2 and NGF, members of the WNT singling pathway (Ohlmann and Tamm, 2012) and TGF pathway (Garcia et al., 2017). Sox11 is also reported to regulate the expression of BDNF (Salerno et al., 2012; Struebing et al., 2017) and GNDF (Jankowski et al., 2018), neurotropic factors known to regulate neuronal survival (Pfisterer and Khodosevich, 2017). It would not be surprising if some of these downstream targets of Sox11 were responsible for the cell extrinsic effects associated with the partial knockout of Sox11 in the retina.

We also observed that RGCs transduced with AAV vectors were more susceptible to ONC injury than non-transduced RGCs in the same retina. At the present time we have no direct evidence to explain this apparent difference in survival; however, it is clear that there is a decrease in the survival rate of AAV transduced RGCs. There are two potential explanations for this AAV induced susceptibility. The first is that AAV2 specifically transduces RGCs that are more susceptible to injury. Although, we do not have any direct evidence to prove this hypothesis, we do know that there is cell type selectivity in AAV transduction (Dinculescu et al., 2005; Belur et al., 2008; Watakabe et al., 2015; Smith and Chauhan, 2018). A second possibility is that the transduction by AAV-GFP itself could make RGCs be more sensitive to damage, for example, caused by some toxic effect of AAV- GFP vector (Khabou et al., 2018). It is also possible that the expression of GFP itself may result in increased susceptibility to injury (Ganini et al., 2017). Independent of the mechanism, our data reveals that the transduced cells are more susceptible to death following ONC.

In the PNS, similar response of dorsal root ganglion neurons to peripheral nerve injury was found. Sox11 is dramatically upregulated in the dorsal root ganglion following injury to the peripheral nerve and plays a pivotal role in axonal regeneration (Jankowski et al., 2009). Three days after the transection of the sciatic nerve in the rat, there is a $1004 \%$ increase in Sox 11 in 

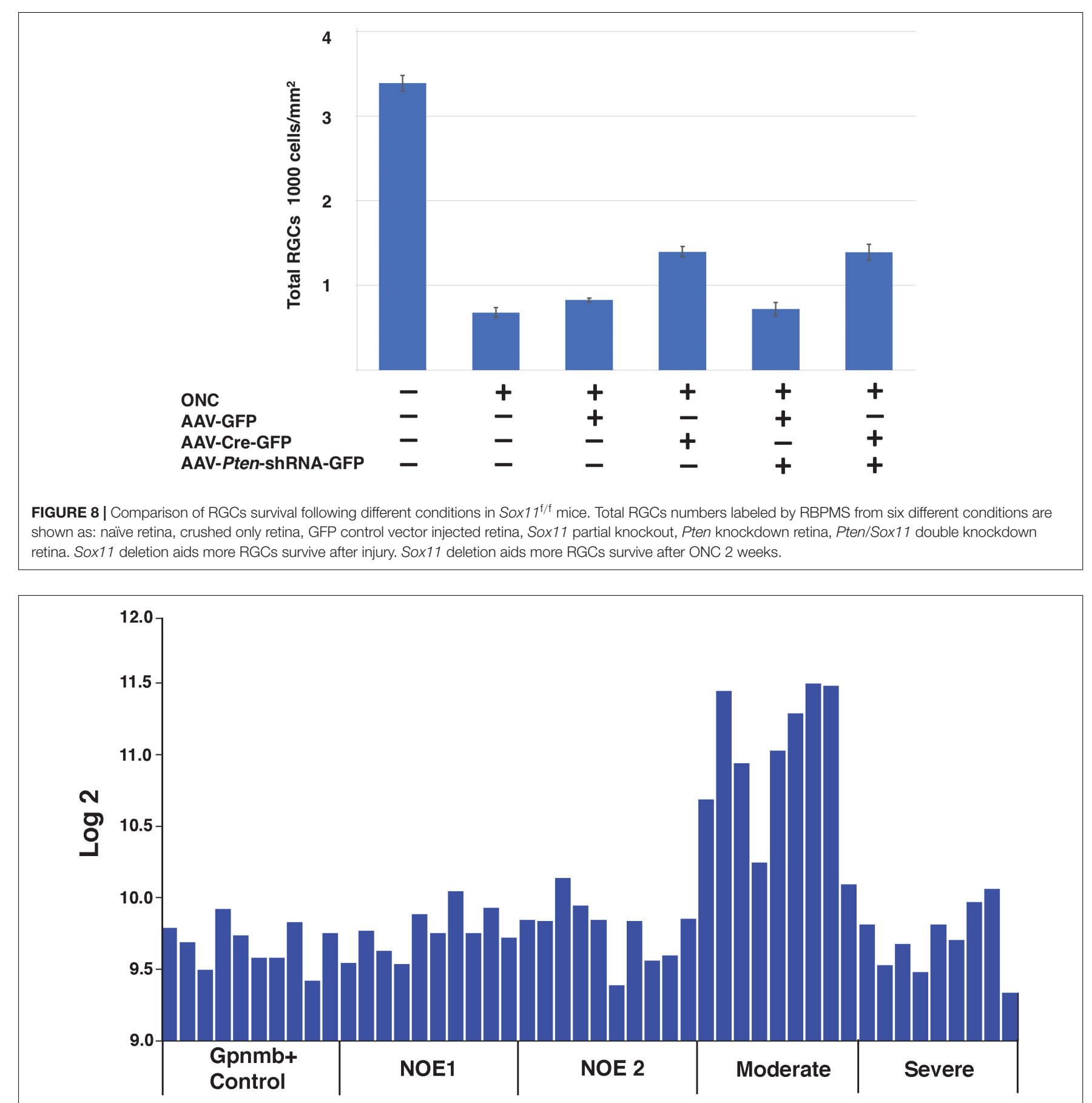

FIGURE 9 | Sox11 mRNA Levels in Pigmentary Glaucoma. Sox11 levels in a meta-analysis of a DBA/2J mouse pigmentary glaucoma dataset from Howell et al. (2011). The ordinate represents the Sox11 mRNA level from microarrays, expressed in $\log _{2}$, scaled with the mean set to 8 . The mice were classified as wild type Gpnmb $+1+$ controls (Gpnmb+ Controls), no detectable glaucoma 1 (NOE 1), no detectable glaucoma 2 (NOE2), moderate glaucoma (Moderate), and severe glaucoma (Severe). Other than the wild type group, all the groups were Gpnmb ${ }^{-1-}$. Notice that there is a dramatic increase in Sox 11 expression during early phases of glaucoma in this mouse model. As the ganglion cells die in severe glaucoma, the expression levels of Sox11 decrease. These data suggest that Sox 11 is an early marker for retinal injury. This general expression pattern was observed for the following 5 of the 6 Affymetrix probe sets targeting Sox11: 1429051_s_at (illustrated above), 1453002_at, 1429372_at, 1453125_at, and 1431225_at.

the dorsal root ganglion and these levels remain elevated for at least the next 4 days (Jankowski et al., 2009). By 4 weeks after transection, Sox11 levels returned to baseline. This upregulation and sustained expression of Sox11 is critical to the survival of the dorsal root ganglion neurons and the regeneration of peripheral axons along the injured nerve. When the levels of Sox11 were 


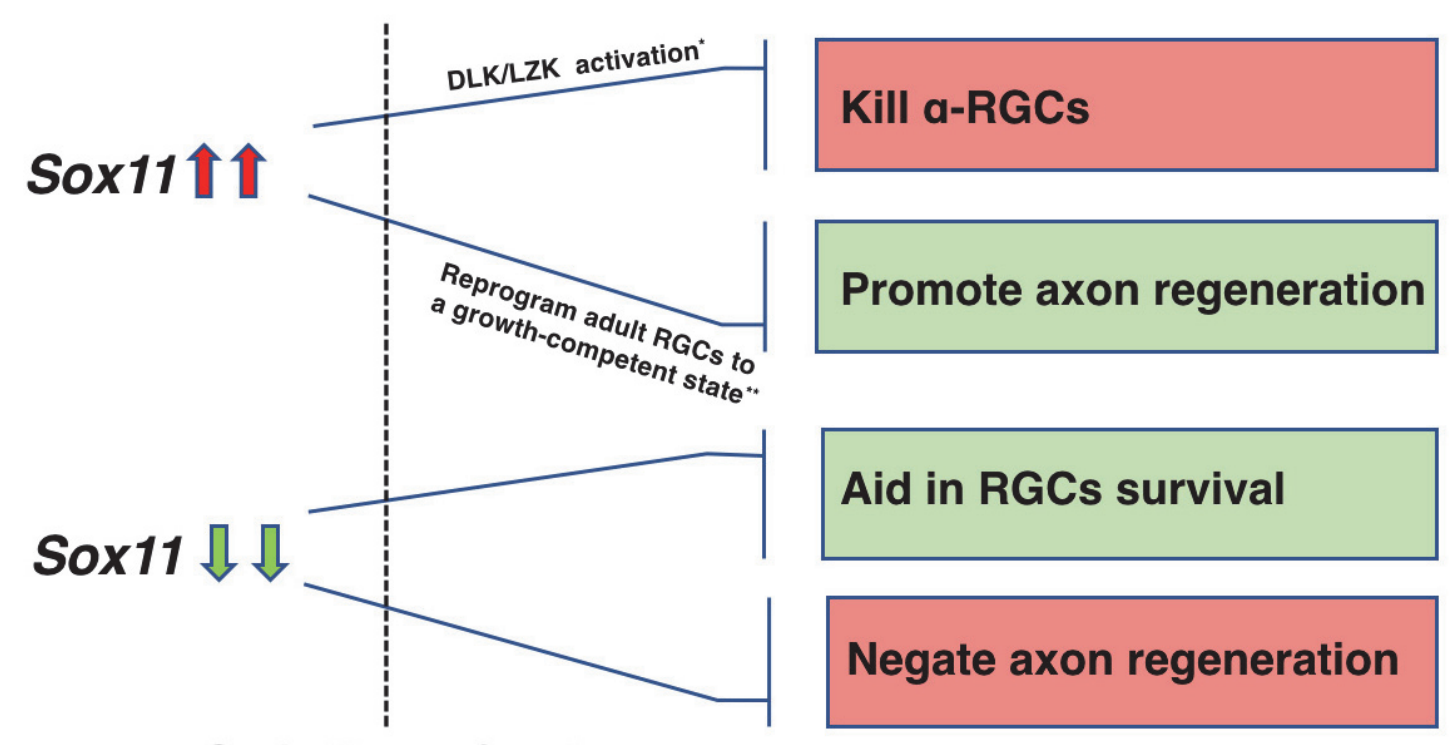

Optic Nerve Crush

FIGURE 10 | A schematic illustration depicting the role of Sox11 regulation in RGCs survival and axon regeneration. The differential response is observed in both overexpressing Sox 11 or knocking-down Sox 11. Upregulation of Sox11 promotes robust axon regeneration of some RGCs types but kills $\alpha$-RGCs (Norsworthy et al., 2017). Downregulation of Sox11 aids RGCs survival (Welsbie et al., 2017) but negates the axon regeneration facilitated by Pten deletion.

knocked down by delivery of siRNA in an in vitro study, there was an increase in neural apoptosis as well as a decrease in neurite outgrowth (Jankowski et al., 2006). It showed that apoptosisrelated genes that are regulated by Sox11, like Tank, Bnip3, Blk and Bcl10, may therefore contribute to the increased number of apoptotic cells in the Sox11-deficient cells. It seems likely that this result is not completely consistent with ours. Potential reasons include different experimental conditions (in vivo or in vitro), or different cultured cells. Jankowski showed that In vivo, Sox11 knockdown reduced the elevation of ATF3 following PNS injury, whereas in vitro, this knockdown led to a decrease in ATF3 expression (Jankowski et al., 2009).

Recently, Welsbie et al. (2017) identified Sox11, as a major downstream mediator of RGC death through DLK/LZK signal activation. Their data with human stem cell-derived RGCs showed that after injury, primary RGCs increased Sox11 mRNA expression. Moreover, Sox11 knockdown had a survivalpromoting effect on injured RGCs, which is consistent with our findings in vivo. Norsworthy et al. (2017), who were also using an in vivo approach, found that SOX11 is preferentially involved in the death of alpha RGCs. In addition, their data also implicated Sox11 in axon regeneration following ONC. In our study, we further verified that downregulation of Sox11 counters axon regeneration facilitated by Pten knockdown. A similar decrease in axonal regeneration occurred in vivo after Sox11 knockdown in the dorsal root ganglion (Jankowski et al., 2009). Thus, the upregulation of Sox11 is believed to be necessary for the normal regeneration of axons in the peripheral nerve. Jankowski et al. (2006) pointed out that one possible transcriptional target of SOX11, ARPC3, a protein that is thought to contribute to actin filament nucleation, may be involved in neurite extension and branching (Jankowski et al., 2006). Although further validation is required in the future, this finding still provides new insight underlying axon growth, and how the injury signal is relayed to the cell body, resulting in either cell death or regenerative response. Interestingly, Sox11 was also upregulated when the central projection of the dorsal root was severed; however, the degree of upregulation was lower, only $51 \%$ (Jankowski et al., 2006, 2009). The most parsimonious explanation is that these neurons are attempting to survive using the same program that is successful in peripheral nerve injury; however, other influences derail the regenerative program, causing the cell to abort the regenerative process and, in many cases, cause subsequent neuronal death (Geisert et al., 1996; Schwab and Bartholdi, 1996; Silver and Miller, 2004; Harel and Strittmatter, 2006). Recent evidence indicates that these inhibitory influences can at least be partially averted by stimulating the ganglion cells to regrow their axons (Leibinger et al., 2009; Muller et al., 2009; Park et al., 2009, 2010; Smith et al., 2009; de Lima et al., 2012; Pernet et al., 2013).

SOX11 plays a critical role in regulating neuronal development, and has a potential promotion effect on axon regeneration. The effect of SOX11 appears to be dependent on the surrounding environment: it can either be reprogramming, or dedifferentiating (Aubert et al., 1995). Given that upregulation of Sox11 is among the initial responses of the neuron to injury and that this response is intact in RGCs, it may be possible to identify where the transcriptional cascade leading to axon regeneration and cell survival in the CNS differs from that in peripheral nerve injury. Taken together, we found different neuron components (cell body and axons) may respond uniquely to genetic modulation. This differential response is observed 
in both overexpressing Sox11 or knocking-down Sox11. We found that a partial knockout of Sox11 resulted in an increase in RGC survival and a decrease in axonal regeneration; while, Norsworthy et al. (2017) found that over expressing Sox11 had the opposite effect with a selective loss of specific RGC cell types and a facilitation of axonal regeneration (Figure 10). Therefore, in the future treatment of neural repair and axon regeneration, gene therapy is recommended to be designed specifically for multiple therapeutic targets to achieve optimal outcomes for neural recovery.

\section{AUTHOR CONTRIBUTIONS}

YL, FS, and EG contributed design of this study and drafted the article. JW performed all ONC procedures and data analysis. RK was responsible for animal breeding, assisted with all animal surgeries and isolated RNA from samples. YL performed intravitreal injections and immunostaining. All authors contributed to manuscript revision, read and approved the submitted version.

\section{REFERENCES}

Aubert, I., Ridet, J. L., and Gage, F. H. (1995). Regeneration in the adult mammalian CNS: guided by development. Curr. Opin. Neurobiol. 5, 625-635. doi: 10.1016/ 0959-4388(95)80068-9

Barnstable, C. J., and Drager, U. C. (1984). Thy-1 antigen: a ganglion cell specific marker in rodent retina. Neuroscience 11, 847-855. doi: 10.1016/0306-4522(84) 90195-7

Belur, L. R., Kaemmerer, W. F., Mcivor, R. S., and Low, W. C. (2008). Adenoassociated virus type 2 vectors: transduction and long-term expression in cerebellar Purkinje cells in vivo is mediated by the fibroblast growth factor receptor 1 : bFGFR-1 mediates AAV2 transduction of Purkinje cells. Arch. Virol. 153, 2107-2110. doi: 10.1007/s00705-008-0222-7

Bergsland, M., Ramskold, D., Zaouter, C., Klum, S., Sandberg, R., and Muhr, J. (2011). Sequentially acting sox transcription factors in neural lineage development. Genes Dev. 25, 2453-2464. doi: 10.1101/gad.176008.111

Bergsland, M., Werme, M., Malewicz, M., Perlmann, T., and Muhr, J. (2006). The establishment of neuronal properties is controlled by Sox 4 and Sox11. Genes Dev. 20, 3475-3486. doi: 10.1101/gad.403406

Bhattaram, P., Penzo-Mendez, A., Sock, E., Colmenares, C., Kaneko, K. J., Vassilev, A., et al. (2010). Organogenesis relies on SoxC transcription factors for the survival of neural and mesenchymal progenitors. Nat. Commun. 1:9. doi: $10.1038 /$ ncomms 1008

Carlstedt, T. (1997). Nerve fibre regeneration across the peripheral-central transitional zone. J. Anat. 190(Pt 1), 51-56. doi: 10.1046/j.1469-7580.1997. 19010051.x

Chandran, V., Coppola, G., Nawabi, H., Omura, T., Versano, R., Huebner, E. A., et al. (2016). A systems-level analysis of the peripheral nerve intrinsic axonal growth program. Neuron 89, 956-970. doi: 10.1016/j.neuron.2016. 01.034

Chang, K. C., Hertz, J., Zhang, X., Jin, X. L., Shaw, P., Derosa, B. A., et al. (2017). Novel regulatory mechanisms for the SoxC transcriptional network required for visual pathway development. J. Neurosci. 37, 4967-4981. doi: 10.1523/ JNEUROSCI.3430-13.2017

de Lima, S., Koriyama, Y., Kurimoto, T., Oliveira, J. T., Yin, Y., Li, Y., et al. (2012). Full-length axon regeneration in the adult mouse optic nerve and partial recovery of simple visual behaviors. Proc. Natl. Acad. Sci. U.S.A. 109, 9149-9154. doi: 10.1073/pnas.1119449109

Dinculescu, A., Glushakova, L., Min, S. H., and Hauswirth, W. W. (2005). Adenoassociated virus-vectored gene therapy for retinal disease. Hum. Gene Ther. 16, 649-663. doi: 10.1089/hum.2005.16.649

\section{FUNDING}

This work was supported by DoD Grant W81XWH-12-1-0255 from the United States Army Medical Research and Materiel Command and the Telemedicine and Advanced Technology (to EG), Vision Core Grant P030EY006360, and an Unrestricted Grant from Research to Prevent Blindness. This publication was supported in part by the Emory Integrated Genomics Core (EIGC) Shared Resource of Winship Cancer Institute of Emory University and NIH/NCI under award number P30CA138292.

\section{ACKNOWLEDGMENTS}

We thank Steven G. Hart and XiangDi Wang for their early technical work on this project. We also thank Rafi Ahmed and Ali Ellebedy from Department of Microbiology and Immunology in Emory University for giving Sox $11^{\mathrm{f} / \mathrm{f}}$ mice as a gift. We thank Veronique Lefebvre at Cleveland Clinic who originally created the Sox $11^{\mathrm{f} / \mathrm{f}}$ mice. We also thank Fred Gage for the AAV-Cre-GFP vector.

Freeman, N. E., Templeton, J. P., Orr, W. E., Lu, L., Williams, R. W., and Geisert, E. E. (2011). Genetic networks in the mouse retina: growth associated protein 43 and phosphatase tensin homolog network. Mol. Vis. 17, 1355-1372.

Gan, L., Xiang, M., Zhou, L., Wagner, D. S., Klein, W. H., and Nathans, J. (1996). POU domain factor Brn-3b is required for the development of a large set of retinal ganglion cells. Proc. Natl. Acad. Sci. U.S.A. 93, 3920-3925. doi: 10.1073/ pnas.93.9.3920

Ganini, D., Leinisch, F., Kumar, A., Jiang, J., Tokar, E. J., Malone, C. C., et al. (2017). Fluorescent proteins such as eGFP lead to catalytic oxidative stress in cells. Redox Biol. 12, 462-468. doi: 10.1016/j.redox.2017.03.002

Garcia, T. B., Hollborn, M., and Bringmann, A. (2017). Expression and signaling of NGF in the healthy and injured retina. Cytokine Growth Factor Rev. 34, 43-57. doi: 10.1016/j.cytogfr.2016.11.005

Geisert, E. E. Jr., Bidanset, D. J., Del Mar, N., and Robson, J. A. (1996). Upregulation of a keratan sulfate proteoglycan following cortical injury in neonatal rats. Int. J. Dev. Neurosci. 14, 257-267. doi: 10.1016/0736-5748(96)00012-3

Geisert, E. E., Lu, L., Freeman-Anderson, N. E., Templeton, J. P., Nassr, M., Wang, X., et al. (2009). Gene expression in the mouse eye: an online resource for genetics using 103 strains of mice. Mol. Vis. 15, 1730-1763.

Harel, N. Y., and Strittmatter, S. M. (2006). Can regenerating axons recapitulate developmental guidance during recovery from spinal cord injury? Nat. Rev. Neurosci. 7, 603-616. doi: 10.1038/nrn1957

Haslinger, A., Schwarz, T. J., Covic, M., and Lie, D. C. (2009). Expression of Sox11 in adult neurogenic niches suggests a stage-specific role in adult neurogenesis. Eur. J. Neurosci. 29, 2103-2114. doi: 10.1111/j.1460-9568.2009.06768.x

Hines-Beard, J., Marchetta, J., Gordon, S., Chaum, E., Geisert, E. E., and Rex, T. S. (2012). A mouse model of ocular blast injury that induces closed globe anterior and posterior pole damage. Exp. Eye Res. 99, 63-70. doi: 10.1016/j.exer.2012. 03.013

Howell, G. R., Macalinao, D. G., Sousa, G. L., Walden, M., Soto, I., Kneeland, S. C., et al. (2011). Molecular clustering identifies complement and endothelin induction as early events in a mouse model of glaucoma. J. Clin. Invest. 121, 1429-1444. doi: 10.1172/JCI44646

Jankowski, M. P., Cornuet, P. K., Mcilwrath, S., Koerber, H. R., and Albers, K. M. (2006). SRY-box containing gene 11 (Sox11) transcription factor is required for neuron survival and neurite growth. Neuroscience 143, 501-514. doi: 10.1016/j. neuroscience.2006.09.010

Jankowski, M. P., Mcilwrath, S. L., Jing, X., Cornuet, P. K., Salerno, K. M., Koerber, H. R., et al. (2009). Sox11 transcription factor modulates peripheral nerve regeneration in adult mice. Brain Res. 1256, 43-54. doi: 10.1016/j.brainres.2008. 12.032 
Jankowski, M. P., Miller, L., and Koerber, H. R. (2018). Increased expression of transcription factor SRY-box-containing gene 11 (Sox11) enhances neurite growth by regulating neurotrophic factor responsiveness. Neuroscience 382, 93-104. doi: 10.1016/j.neuroscience.2018.04.037

Jiang, Y., Ding, Q., Xie, X., Libby, R., Lefebvre, V., and Gan, L. (2013). Transcription factors SOX4 and SOX11 function redundantly to regulate the development of mouse retinal ganglion cells. J. Biol. Chem. 288, 18429-18438. doi: 10.1074/jbc. M113.478503

Jing, X., Wang, T., Huang, S., Glorioso, J. C., and Albers, K. M. (2012). The transcription factor Sox11 promotes nerve regeneration through activation of the regeneration-associated gene Sprrla. Exp. Neurol. 233, 221-232. doi: 10. 1016/j.expneurol.2011.10.005

Kaspar, B. K., Vissel, B., Bengoechea, T., Crone, S., Randolph-Moore, L., Muller, R., et al. (2002). Adeno-associated virus effectively mediates conditional gene modification in the brain. Proc. Natl. Acad. Sci. U.S.A. 99, 2320-2325. doi: 10.1073/pnas.042678699

Khabou, H., Cordeau, C., Pacot, L., Fisson, S., and Dalkara, D. (2018). Dosage thresholds and influence of transgene cassette in adeno-associated virus-related toxicity. Hum. Gene Ther. 29, 1235-1241. doi: 10.1089/hum.2018.144

Kuo, P. Y., Leshchenko, V. V., Fazzari, M. J., Perumal, D., Gellen, T., He, T., et al. (2015). High-resolution chromatin immunoprecipitation (ChIP) sequencing reveals novel binding targets and prognostic role for SOX11 in mantle cell lymphoma. Oncogene 34, 1231-1240. doi: 10.1038/onc.2014.44

Kuwajima, T., Soares, C. A., Sitko, A. A., Lefebvre, V., and Mason, C. (2017). SoxC transcription factors promote contralateral retinal ganglion cell differentiation and axon guidance in the mouse visual system. Neuron 93:e1115. doi: 10.1016/ j.neuron.2017.01.029

Leibinger, M., Muller, A., Andreadaki, A., Hauk, T. G., Kirsch, M., and Fischer, D. (2009). Neuroprotective and axon growth-promoting effects following inflammatory stimulation on mature retinal ganglion cells in mice depend on ciliary neurotrophic factor and leukemia inhibitory factor. J. Neurosci. 29, 14334-14341. doi: 10.1523/JNEUROSCI.2770-09.2009

McCurley, A. T., and Callard, G. V. (2010). Time course analysis of gene expression patterns in zebrafish eye during optic nerve regeneration. J. Exp. Neurosci. 2010, 17-33. doi: 10.4137/JEN.S5006

Moore, D. L., and Goldberg, J. L. (2011). Multiple transcription factor families regulate axon growth and regeneration. Dev. Neurobiol. 71, 1186-1211. doi: 10.1002/dneu.20934

Mu, L., Berti, L., Masserdotti, G., Covic, M., Michaelidis, T. M., Doberauer, K., et al. (2012). SoxC transcription factors are required for neuronal differentiation in adult hippocampal neurogenesis. J. Neurosci. 32, 3067-3080. doi: 10.1523/ JNEUROSCI.4679-11.2012

Mu, X., Beremand, P. D., Zhao, S., Pershad, R., Sun, H., Scarpa, A., et al. (2004). Discrete gene sets depend on POU domain transcription factor Brn3b/Brn3.2/POU4f2 for their expression in the mouse embryonic retina. Development 131, 1197-1210. doi: 10.1242/dev.01010

Muller, A., Hauk, T. G., Leibinger, M., Marienfeld, R., and Fischer, D. (2009). Exogenous CNTF stimulates axon regeneration of retinal ganglion cells partially via endogenous CNTF. Mol. Cell. Neurosci. 41, 233-246. doi: 10.1016/j.mcn. 2009.03.002

Munguba, G. C., Geisert, E. E., Williams, R. W., Tapia, M. L., Lam, D. K., Bhattacharya, S. K., et al. (2013). Effects of glaucoma on Chrna6 expression in the retina. Curr. Eye Res. 38, 150-157. doi: 10.3109/02713683.2012. 724512

Norsworthy, M. W., Bei, F., Kawaguchi, R., Wang, Q., Tran, N. M., Li, Y., et al. (2017). Sox 11 expression promotes regeneration of some retinal ganglion cell types but kills others. Neuron 94:e1114. doi: 10.1016/j.neuron.2017. 05.035

Ohlmann, A., and Tamm, E. R. (2012). Norrin: molecular and functional properties of an angiogenic and neuroprotective growth factor. Prog. Retin. Eye Res. 31, 243-257. doi: 10.1016/j.preteyeres.2012.02.002

Park, K. K., Hu, Y., Muhling, J., Pollett, M. A., Dallimore, E. J., Turnley, A. M., et al. (2009). Cytokine-induced SOCS expression is inhibited by cAMP analogue: impact on regeneration in injured retina. Mol. Cell. Neurosci. 41, 313-324. doi: 10.1016/j.mcn.2009.04.002

Park, K. K., Liu, K., Hu, Y., Kanter, J. L., and He, Z. (2010). PTEN/mTOR and axon regeneration. Exp. Neurol. 223, 45-50. doi: 10.1016/j.expneurol.2009. 12.032
Park, K. K., Liu, K., Hu, Y., Smith, P. D., Wang, C., Cai, B., et al. (2008). Promoting axon regeneration in the adult CNS by modulation of the PTEN/mTOR pathway. Science 322, 963-966. doi: 10.1126/science.1161566

Parker, C. C., Dickson, P. E., Philip, V. M., Thomas, M., and Chesler, E. J. (2017). Systems genetic analysis in genenetwork.org. Curr. Protoc. Neurosci. 79, 8.39.1-8.39.20. doi: 10.1002/cpns.23

Pernet, V., Joly, S., Jordi, N., Dalkara, D., Guzik-Kornacka, A., Flannery, J. G., et al. (2013). Misguidance and modulation of axonal regeneration by Stat 3 and Rho/ROCK signaling in the transparent optic nerve. Cell Death Dis. 4:e734. doi: $10.1038 /$ cddis. 2013.266

Pfisterer, U., and Khodosevich, K. (2017). Neuronal survival in the brain: neuron type-specific mechanisms. Cell Death Dis. 8:e2643. doi: 10.1038/cddis. 2017.64

Pillai-Kastoori, L., Wen, W., and Morris, A. C. (2015). Keeping an eye on SOXC proteins. Dev. Dyn. 244, 367-376. doi: 10.1002/dvdy.24235

Pillai-Kastoori, L., Wen, W., Wilson, S. G., Strachan, E., Lo-Castro, A., Fichera, M., et al. (2014). Sox11 is required to maintain proper levels of Hedgehog signaling during vertebrate ocular morphogenesis. PLoS Genet. 10:e1004491. doi: 10. 1371/journal.pgen.1004491

Prasov, L., and Glaser, T. (2012). Dynamic expression of ganglion cell markers in retinal progenitors during the terminal cell cycle. Mol. Cell. Neurosci. 50, 160-168. doi: 10.1016/j.mcn.2012.05.002

Ramón, Y., Cajal, S., and May, R. M. (1928). Degeneration \& Regeneration of the Nervous System. London: Oxford university press.

Salerno, K. M., Jing, X., Diges, C. M., Cornuet, P. K., Glorioso, J. C., and Albers, K. M. (2012). Sox11 modulates brain-derived neurotrophic factor expression in an exon promoter-specific manner. J. Neurosci. Res. 90, 1011-1019. doi: $10.1002 /$ jnr. 23010

Schepers, G. E., Teasdale, R. D., and Koopman, P. (2002). Twenty pairs of sox: extent, homology, and nomenclature of the mouse and human sox transcription factor gene families. Dev. Cell 3, 167-170. doi: 10.1016/S1534-5807(02)00 223-X

Schwab, M. E., and Bartholdi, D. (1996). Degeneration and regeneration of axons in the lesioned spinal cord. Physiol. Rev. 76, 319-370. doi: 10.1152/physrev.1996. 76.2 .319

Silver, J., and Miller, J. H. (2004). Regeneration beyond the glial scar. Nat. Rev. Neurosci. 5, 146-156. doi: 10.1038/nrn1326

Smith, C. A., and Chauhan, B. C. (2018). In vivo imaging of adeno-associated viral vector labelled retinal ganglion cells. Sci. Rep. 8:1490. doi: 10.1038/s41598-01819969-9

Smith, P. D., Sun, F., Park, K. K., Cai, B., Wang, C., Kuwako, K., et al. (2009). SOCS3 deletion promotes optic nerve regeneration in vivo. Neuron 64, 617-623. doi: 10.1016/j.neuron.2009.11.021

Struebing, F. L., Wang, J., Li, Y., King, R., Mistretta, O. C., English, A. W., et al. (2017). Differential expression of Sox 11 and Bdnf mRNA isoforms in the injured and regenerating nervous systems. Front. Mol. Neurosci. 10:354. doi: 10.3389/fnmol.2017.00354

Surgucheva, I., Weisman, A. D., Goldberg, J. L., Shnyra, A., and Surguchov, A. (2008). Gamma-synuclein as a marker of retinal ganglion cells. Mol. Vis. 14, $1540-1548$.

Tanabe, K., Bonilla, I., Winkles, J. A., and Strittmatter, S. M. (2003). Fibroblast growth factor-inducible-14 is induced in axotomized neurons and promotes neurite outgrowth. J. Neurosci. 23, 9675-9686. doi: 10.1523/JNEUROSCI.2329-09675.2003

Tanaka, S., Kamachi, Y., Tanouchi, A., Hamada, H., Jing, N., and Kondoh, H. (2004). Interplay of SOX and POU factors in regulation of the Nestin gene in neural primordial cells. Mol. Cell. Biol. 24, 8834-8846. doi: 10.1128/MCB.24.20. 8834-8846.2004

Templeton, J. P., Freeman, N. E., Nickerson, J. M., Jablonski, M. M., Rex, T. S., Williams, R. W., et al. (2013). Innate immune network in the retina activated by optic nerve crush. Invest. Ophthalmol. Vis. Sci. 54, 2599-2606. doi: 10.1167/ iovs.12-11175

Templeton, J. P., and Geisert, E. E. (2012). A practical approach to optic nerve crush in the mouse. Mol. Vis. 18, 2147-2152.

Usui, A., Iwagawa, T., Mochizuki, Y., Iida, A., Wegner, M., Murakami, A., et al. (2013a). Expression of Sox4 and Sox11 is regulated by multiple mechanisms during retinal development. FEBS Lett. 587, 358-363. doi: 10.1016/j.febslet. 2012.12.017 
Usui, A., Mochizuki, Y., Iida, A., Miyauchi, E., Satoh, S., Sock, E., et al. (2013b). The early retinal progenitor-expressed gene Sox11 regulates the timing of the differentiation of retinal cells. Development 140, 740-750. doi: 10.1242/dev. 090274

Vazquez-Chona, F. R., and Geisert, E. E. (2012). Networks modulating the retinal response to injury: insights from microarrays, expression genetics, and bioinformatics. Adv. Exp. Med. Biol. 723, 649-656. doi: 10.1007/978-1-46140631-0_82

Wang, J., Li, Y., King, R., Struebing, F. L., and Geisert, E. E. (2018). Optic nerve regeneration in the mouse is a complex trait modulated by genetic background. Mol. Vis. 24, 174-186.

Wang, Y., Lin, L., Lai, H., Parada, L. F., and Lei, L. (2013). Transcription factor Sox11 is essential for both embryonic and adult neurogenesis. Dev. Dyn. 242, 638-653. doi: 10.1002/dvdy.23962

Wang, Z., Reynolds, A., Kirry, A., Nienhaus, C., and Blackmore, M. G. (2015). Overexpression of Sox11 promotes corticospinal tract regeneration after spinal injury while interfering with functional recovery. J. Neurosci. 35, 3139-3145. doi: 10.1523/JNEUROSCI.2832-14.2015

Watakabe, A., Ohtsuka, M., Kinoshita, M., Takaji, M., Isa, K., Mizukami, H., et al. (2015). Comparative analyses of adeno-associated viral vector serotypes $1,2,5,8$ and 9 in marmoset, mouse and macaque cerebral cortex. Neurosci. Res. 93, 144-157. doi: 10.1016/j.neures.2014. 09.002
Welsbie, D. S., Mitchell, K. L., Jaskula-Ranga, V., Sluch, V. M., Yang, Z., Kim, J., et al. (2017). Enhanced functional genomic screening identifies novel mediators of dual leucine zipper kinase-dependent injury signaling in neurons. Neuron 94, 1142.e-1154.e. doi: 10.1016/j.neuron.2017.06.008

Wen, W., Pillai-Kastoori, L., Wilson, S. G., and Morris, A. C. (2015). Sox4 regulates choroid fissure closure by limiting Hedgehog signaling during ocular morphogenesis. Dev. Biol. 399, 139-153. doi: 10.1016/j.ydbio.2014.12.026

Zukor, K., Belin, S., Wang, C., Keelan, N., Wang, X., and He, Z. (2013). Short hairpin RNA against PTEN enhances regenerative growth of corticospinal tract axons after spinal cord injury. J. Neurosci. 33, 15350-15361. doi: 10.1523/ JNEUROSCI.2510-13.2013

Conflict of Interest Statement: The authors declare that the research was conducted in the absence of any commercial or financial relationships that could be construed as a potential conflict of interest.

Copyright (c) 2018 Li, Struebing, Wang, King and Geisert. This is an open-access article distributed under the terms of the Creative Commons Attribution License (CC BY). The use, distribution or reproduction in other forums is permitted, provided the original author(s) and the copyright owner(s) are credited and that the original publication in this journal is cited, in accordance with accepted academic practice. No use, distribution or reproduction is permitted which does not comply with these terms. 